\title{
Energy Evolution Law and Fractal Characteristics of Different Rock Specimen Sizes on Dynamic Compression
}

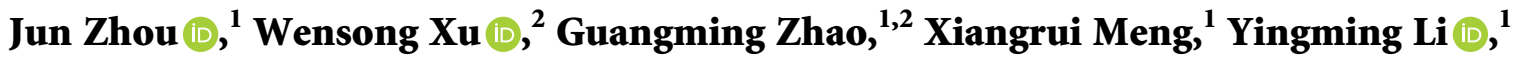 \\ Xukun Wu, ${ }^{1}$ Yuguang $\mathrm{Li}^{2}$, and Xiang Cheng ${ }^{1}{ }^{1}$ \\ ${ }^{1}$ State Key Laboratory of Deep Coal Mine Mining Response and Disaster Prevention and Control, \\ Anhui University of Science and Technology, Huainan 232000, Anhui, China \\ ${ }^{2}$ School of Safety Science and Engineering, Anhui University of Science and Technology, Huainan 232000, Anhui, China
}

Correspondence should be addressed to Wensong Xu; 359879021@qq.com

Received 2 December 2021; Accepted 27 January 2022; Published 17 February 2022

Academic Editor: Shijin Li

Copyright (c) 2022 Jun Zhou et al. This is an open access article distributed under the Creative Commons Attribution License, which permits unrestricted use, distribution, and reproduction in any medium, provided the original work is properly cited.

To explore the broken energy change and the specimen fragment influence of granite where the length-to-diameter ratio is $0.5-2$, the SHPB device was used to perform dynamic loading on the granite specimens. The rock energy evolution law was analyzed by the energy time history curve, and according to rock fragment characteristics, the rock fractal dimension was calculated. The experimental results show that the rock energy-time history curve can be divided into four stages. The incident energy is independent of the length-to-diameter ratio of the rock specimens. When the length-to-diameter ratio of the rock specimens is $0.5-0.9$, the difference of incident energy, transmitted energy, and reflection energy of rock specimens is small. With the length-todiameter ratio increasing, the rock fragment size became larger. These rock fragments have good self-similarity. The rock specimen fractal dimension is at least 1.94, and the maximum $D$ is 2.536 . And with the length-to-diameter ratios increasing, the fractal dimension of rock specimens decreases. With the specimen fractal dimension increasing, the energy dissipation density of rock specimens also increases. The higher the energy dissipation density of a rock specimen, the more uniform rock fragments are.

\section{Introduction}

Rock fragmentation law under impact load is the basis for the study of mining, geotechnical blasting, and so on [1-3]. The process of rock fracture under impact load is also the process of energy-driven transformation from a stable state to an unstable state. Rock damage degree is closely related to energy dissipation. Rock size is one of the factors affecting the mechanical properties of rock, and the size affects the degree of rock failure. It is of great significance to understand the dissipation characteristics and broken characteristics in rock, as they are helpful for ore yield and energy utilization rate.

Rock size effects have been studied in many ways at home and abroad. Tanusree [4] used SHPB to impact different rocks to study the size effect and combined it with static experiments to analyse the size effect. Jin [5] established a constitutive model and explained the concrete size effect on tensile strength. Chen [6] studied the concrete size effect under axial compression and proposed a related stressstrain constitutive model. Li et al. [7] studied the rock fragment characteristics at different strain rates and established the fragmentation model to predict the rock fragment size.

It is great significance to study the energy evolution law, fragmentation form, and fragment distribution characteristics of rock fragmentation under impact load [8-11]. Zhang et al. [12] studied the fracture and energy dissipation characteristics of rocks at different loading rates and analyzed the relationship between dissipation energy and absorption energy. Grady [13] used the principle of constant energy, based on the assumption that all the dissipated energy of rocks is used for rock fractures, the rock block and energy formula are established, which can well describe the relationship between ductility and brittle material. Lundberg [14] studied the rock distribution and energy absorption 
characteristics through the SHPB device. According to the characteristics of rock fragmentation that established two models and analyzed that the greater the incident energy, the more thoroughly the rock fragmentation. Hong et al. [15] used a $75 \mathrm{~mm}$ SHPB device to impact rock and analyzed the energy absorption rate and fragmentation form of rocks at different sizes, and it was concluded that the rock damage is closely related to rock size. After Mandelbrot [16] founded the fractal theory, Tyler et al. $[17,18]$ successively established and developed a mass fractal model for the particle size distribution of rock fragments and was widely used in rocks $[19,20]$.

Granite is a common rock in engineering. In this study, many granites were impacted by SHPB, and the influence of length-to-diameter ratio on incident energy, reflection energy, and transmission energy was analyzed. The distribution characteristics of its fragments are screened and the fractal characteristics of rock specimens with different length-to-diameter ratios are discussed, which has certain engineering significance for revealing the characteristics of rock fragmentation under impact loads.

\section{Test Scheme Design and Testing Apparatus}

2.1. Processing and Preparation of Granite Specimens. This test takes granite as the research object. The unified diameter is $50 \mathrm{~mm}$, and the length is $25 \mathrm{~mm}, 30 \mathrm{~mm}, 35 \mathrm{~mm}, 40 \mathrm{~mm}$, $45 \mathrm{~mm}, 50 \mathrm{~mm}, 60 \mathrm{~mm}, 75 \mathrm{~mm}$, and $100 \mathrm{~mm}$, respectively. These length-to-diameter ratios (LDRs) of specimens are 0.5 , $0.6,0.7,0.8,0.9,1.0,1.2,1.5$, and 2.0 , respectively. In the compression test, the mechanical characteristics and fragments of granite with different high diameter ratios are studied. The rock specimens are processed in accordance with the corresponding specifications. Through a series of procedures such as cored extraction, cutting, and polishing, the rock specimens that meet the requirements are obtained. The plane at both ends of the rock sample is nonparallel $\leq \pm 0.3 \mathrm{~mm}$, and the axis deviation of the vertical specimens at the end surface is $\leq \pm 0.25^{\circ}$. Test specimens were performed under dynamic compression testing under $0.75 \mathrm{MPa}$ impact loading.

2.2. Testing Apparatus and Principle. The test equipment adopts the SHPB device of the dynamic and static combination loading system, which is shown in Figure 1. The input bar, transmission bar, and absorption bar are made of $40 \mathrm{Cr}$ alloy steel, with a density of $7820 \mathrm{~kg} / \mathrm{m}^{3}$, Young's modulus of $210 \mathrm{GPa}$, the diameter of the bar is $50 \mathrm{~mm}$, and elastic limit of the bar is $800 \mathrm{MPa}$. In order to reduce the equipment waveform dispersion, a $1 \mathrm{~mm}$ rubber pad is used as a pulse shaping device at the end of the incident bar. Test specimens are sandwiched between the incident bar and the transmission bar, in order to reduce the friction effect between the pressure bar and the contact surface of the specimen. A Vaseline lubricant is evenly applied to the contact surface of the specimens and the bar.

A high-speed bullet was fired by the SHPB cavity and formed a stress pulse in the incident bar end. The stress pulse forward transmits to the incident bar and specimen interface, due to the difference in the wave impedance of the incident bar and rock specimens. A reflection wave and transmission wave are generated, respectively, at the contact surface. Specimens are much shorter than the bar. The time of the impact pulse transmitted repeatedly is $2 \mathrm{~L} /$ $C$. After a few times, the stress and strain of the specimens' surfaces are basically the same. Through recording the waveform data, we can get the stress-strain relationship of specimens.

The input strain pulse signal, reflected strain pulse signal, and transmitted strain pulse signal are denoted and collected. The three-wave formula to calculate the stress, strain, and average strain rate of the specimens in the impact process is used. The calculation principle as follows [10]:

$$
\left.\begin{array}{l}
\sigma_{s}=\frac{A E}{2 A_{S}}\left[\varepsilon_{t}(t)+\varepsilon_{r}(t)+\varepsilon_{i}(t)\right] \\
\dot{\varepsilon}(t)=\frac{C}{L}\left[\varepsilon_{t}(t)+\varepsilon_{r}(t)-\varepsilon_{i}(t)\right] \\
\varepsilon_{t}(t)=\frac{C}{L} \int_{0}^{t}\left[\varepsilon_{t}(t)+\varepsilon_{r}(t)-\varepsilon_{i}(t)\right] d t
\end{array}\right\},
$$

where $\sigma_{s}$ is the stress of the specimens, $\varepsilon$ is the strain of the specimens, and $\dot{\varepsilon}$ is the strain rate of the specimens. $A, E$, and $C$ are the area, the elastic modulus, and the wave velocity of the bar, respectively. $A_{s}$ and $L$ are the area and length of specimens, respectively. $\varepsilon_{i}(t), \varepsilon_{r}(t)$, and $\varepsilon_{t}(t)$ are the incident strain pulse, the reflected strain pulse, and the transmitted strain pulse at time $t$, respectively.
2.3. Typical Waveform. According to the strain gauge on the incident bar and transmission bar, the incident signal is collected first, and then the transmitted and reflected wave signals are collected. When the LDR of rock specimens is less than 1.2, it can better meet the stress wave balance, and the stress wave equilibrium diagram is shown in Figure 2. 


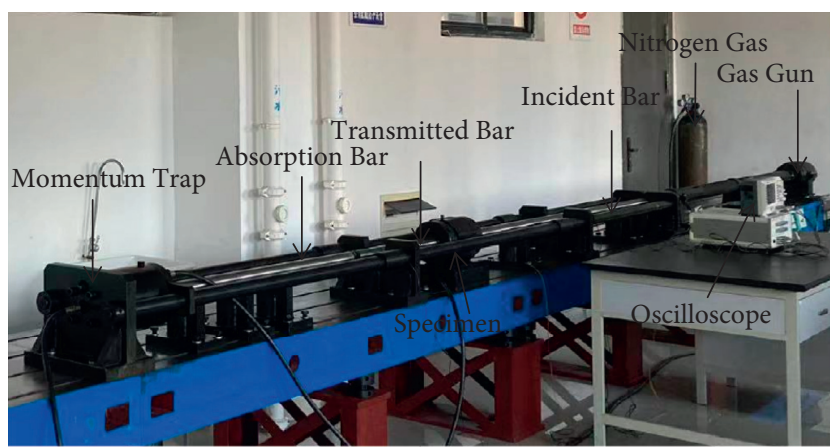

FIGURE 1: SPHB experimental device.

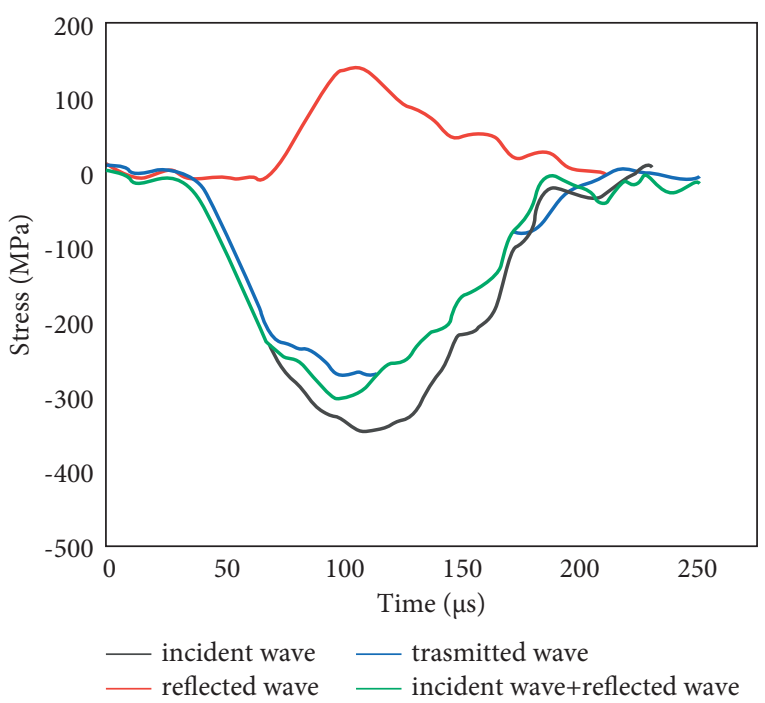

FIgURE 2: Stress wave equilibrium.

\section{Energy Analysis of Granite with Different Length-to-Diameter Ratios}

3.1. Dynamic Stress-Strain Curves of Granite with Different Length-to-Diameter Ratios. The voltage signals were collected, the data were processed with the three-wave method, and the stress-strain curve of the specimen was obtained, as shown in Figure 3.

Stress-strain curves show four characteristic stages. The first stage curves are called the microcrack closure stage. Specimens remain intact at this stage. In the second stage, the curves slope are nearly linear, which is called elastic deformation stage. Specimens appear small cracks in this stage. In the third stage of the curves which occurs in the upper sections, the peak stress is over $70 \%$ and the curves slope gradually decreases to 0 . This is called the plastic deformation stage. Specimens appear to have a lot of cracks in this stage. In the fourth stage of curves, the curves slope are negative, which is called the failure stage. Specimens are damaged in this stage.

The stress peak values are close in different sized specimens. The prepeak curves of different LDR specimens show good consistency, and the postpeak curves are more obvious in larger LDR specimens. The postpeak curves of

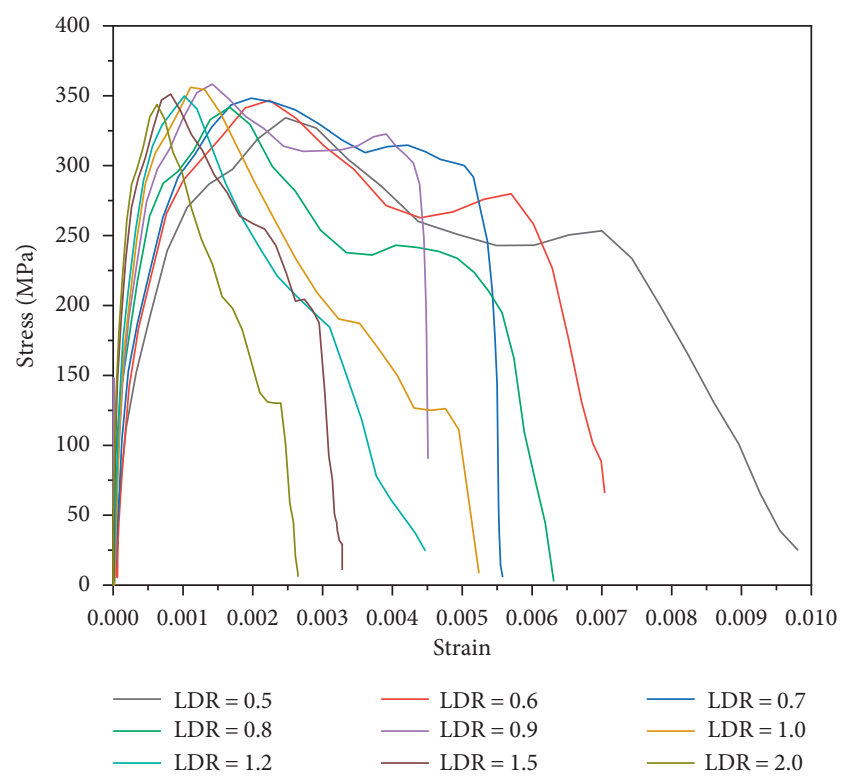

Figure 3: Stress-strain curves of granite.

smaller size specimens show more obvious plastic properties with secondary peaks; the specimen strain also increases.

3.2. Energy Calculation. Cai et al. [21] studied that the lateral inertia effect has few influence on test results when the strain rate is lower than some certain value. The test strain rates are all less than $200 \mathrm{~s}^{-1}$, so the consumed energy of transverse movement can be ignored. Combined the one-dimensional elastic stress wave theory and the stress uniform assumption, the energy is performed by the following equation [21]:

$$
\left.\begin{array}{c}
W_{i}=\frac{A}{\rho C} \int_{0}^{t} \sigma_{i}^{2}(t) \mathrm{d} t \\
W_{r}=\frac{A}{\rho C} \int_{0}^{t} \sigma_{r}^{2}(t) \mathrm{d} t \\
W_{t}=\frac{A}{\rho C} \int_{0}^{t} \sigma_{t}^{2}(t) \mathrm{d} t
\end{array}\right\},
$$

where $W_{i}, W_{r}, W_{t}$, and $W_{d}$ are incident energy, reflection energy, transmission energy, and absorbed energy, respectively.

The statistical distribution of specimens' energy is shown in Table 1 . Under the $0.75 \mathrm{MPa}$ impact pressure, the absorbed energy has no relation with the length-to-diameter ratio and remains stable with the increase of the length-todiameter ratio. Because specimen volume is different, the energy dissipation of rock broken per unit volume is also different. Therefore, in order to reflect the energy absorption of the specimen [15], the energy dissipation density $\left(w_{W d}\right)$ is as follows: 
TABLE 1: Statistical distribution of specimens' energy.

\begin{tabular}{|c|c|c|c|c|c|c|c|}
\hline Impact air (MPa) & LDR & $\sigma(\mathrm{MPa})$ & $\begin{array}{c}\text { Absorbed energy } \\
W_{d}(\mathrm{~J})\end{array}$ & $\begin{array}{l}\text { Reflected energy } \\
\qquad W_{i}(\mathrm{~J})\end{array}$ & $\begin{array}{l}\text { Incident energy } \\
\qquad W_{r}(\mathrm{~J})\end{array}$ & $\begin{array}{l}\text { Transmitted energy } \\
W_{t}(\mathrm{~J})\end{array}$ & $\begin{array}{l}\text { Energy dissipation density } \\
\qquad W_{W d}\left(\mathrm{~J} \cdot \mathrm{cm}^{-3}\right)\end{array}$ \\
\hline \multirow{9}{*}{0.75} & 0.5 & 334.25 & 246.84 & 229.157 & 549.467 & 73.47 & 5.028 \\
\hline & 0.6 & 346.678 & 327.11 & 105.87 & 596.616 & 163.636 & 5.553 \\
\hline & 0.7 & 348.25 & 323.71 & 93.082 & 576.332 & 159.54 & 4.71 \\
\hline & 0.8 & 349.65 & 298.37 & 76.562 & 599.985 & 225.053 & 3.799 \\
\hline & 0.9 & 358.403 & 318.89 & 98.889 & 575.203 & 157.424 & 3.609 \\
\hline & 1.0 & 356.125 & 304.19 & 245.137 & 594.575 & 45.248 & 3.098 \\
\hline & 1.2 & 344.749 & 291.18 & 138.642 & 549.197 & 119.375 & 2.471 \\
\hline & 1.5 & 351.225 & 330.34 & 155.83 & 578.954 & 92.784 & 2.243 \\
\hline & 2 & 343.696 & 307.04 & 209.654 & 579.818 & 63.124 & 1.563 \\
\hline
\end{tabular}

$$
w_{w d}=\frac{W_{d}}{V}
$$

\subsection{Energy Time History Curves and Rock Damage.} Incident energy time history curves of different volume specimens overlap. Transmission energy and reflection energy time history curves of different LDR specimens are different. Transmitted energy and reflected energy time history curves are near when the length-to-diameter ratios are $0.5-0.9$ of specimens. A specimen's transmitted energy is higher than its reflected energy. And with the length-to-diameter ratios of specimens increasing, the transmitted energy decreases. The specimens' reflection energy is higher than the transmitted energy when specimens' length-to-diameter ratios are 1-2. In the process of specimens being broken, the stress state changes constantly. Different volume specimens are in different states at the same time. If the specimen is too short, it is easy to cause a friction effect in the experiment. And if the specimen is too long, it is easy to cause an inertia effect. In the experiment, when specimen lengthto-diameter ratios are in $0.5-0.9$, the time history curves of reflection energy and transmission energy are almost the same. So, when the granite specimens have a diameter of $50 \mathrm{~mm}$ and the length-to-diameter ratios are $0.5-0.9$, the specimens are appropriate. Through a lot of experiments, Davies and Hunter [22] studied that the most appropriate length-to-diameter ratio is $L / R=\sqrt{3} / 2$, and the LDR value is $0.5-0.9$.

Compared with Figure 3 stress-strain curves, Figure 4 energy-time history curves can also be divided into four stages. Such as incident energy, stage 1, when time is in the range of $0-75 \mu s$, the incident energy rises rapidly, and the absorbed energy as a kind of elastic energy is stored in the specimen. Stage 2, when time is in the range of 75-150 $\mu$, the incident energy increases linearly. In the meantime, specimen internal microcracks propagate rapidly and a large number of new microcracks are generated. Stage 3, when time is in the range of $150-175 \mu$ s, the incident energy tends to a stable value. In the meantime, granite specimens crack and undergo axial tensile split, releasing elastic strain energy. Stage 4, after the incident energy is $175 \mu \mathrm{s}$, specimens are completely broken, and incident energy are stable.

\section{Study on Fractal Fracture of Different Length- to-Diameter Ratios in Granite}

4.1. Specimens Fragments Sieving. Sieving mesh with sizes of $2.5 \mathrm{~mm}, 5 \mathrm{~mm}, 10 \mathrm{~mm}, 20 \mathrm{~mm}$, and $50 \mathrm{~mm}$ was selected for screening specimen fragments, and the mass of fragments on the sieving mesh was weighed by precision electronic balance. The sieving test results of specimen fragments are shown in Table 2.

4.2. Specimen Length-to-Diameter Ratio and Dynamic Broken Characteristics. Specimen fragments are divided into five grades that are $0-2.5 \mathrm{~mm}, 2.5 \sim 5 \mathrm{~mm}, 5-10 \mathrm{~mm}, 10-20 \mathrm{~mm}$, and $20-50 \mathrm{~mm}$, respectively. The distribution curves of granite specimen fragments in different length-to-diameter ratios are shown in Figure 5.

In order to quantify specimen fragment size, the fragment average particle size $d_{S}$ is used to characterize the specimen fragment degree $[23,24]$, which is as follows:

$$
d_{s}=\frac{\sum \eta_{i} d_{i}}{\sum \eta_{i}}
$$

where $d_{i}$ is the fragment average size in different sizes sieving mesh; $\eta_{i}$ is the fragment mass percentage of $d_{i}$.

The results of the average fragment size are shown in Table 2. With length-to-diameter ratios increasing, the $d_{s}$ increases gradually, indicating that specimen damage gradually decreases. The $d_{s}$ can calculate specimen fragment degree directly, but it cannot reflect the fragment distribution characteristics intuitively. In other words, the same $d_{s}$ does not mean that the fragments' weight is the same in different sieving mesh. So, it is not possible to quantify the fragment distribution characteristics truly. Many scholars' results show that rock fragment fractal characteristics are in many kinds of rock [25]. According to the mass-fragment correlation, the rock fragment distribution equation is as follows:

$$
Y=\frac{m(x)}{m_{t}}=\left(\frac{x}{x_{m}}\right)^{3-D},
$$

where parameters $x$ and $x_{m}$ are the fragment particle size and the maximum particle size, respectively; $m(x)$ is the cumulative fragment mass that is smaller than $x . m_{t}$ is the total specimen fragment mass. $D$ is the fragment distribution 


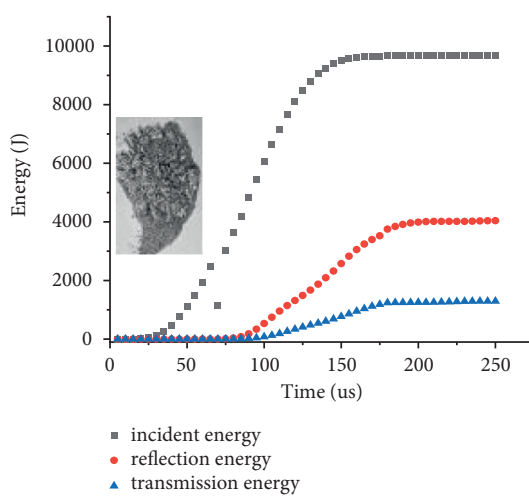

$\mathrm{LDR}=0.5$

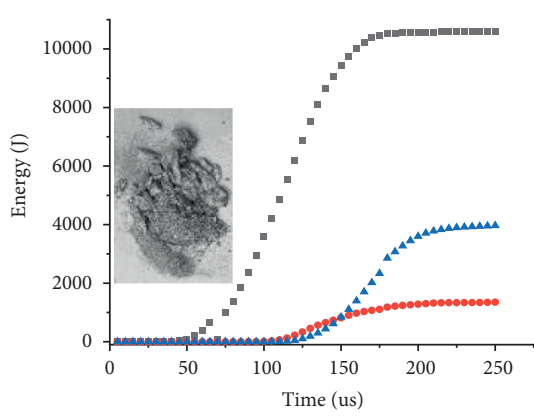

- incident energy

- reflection energy

$\Delta$ transmission energy

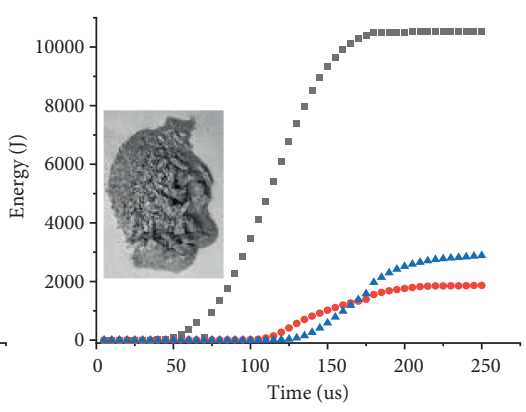

- incident energy

- reflection energy

$\Delta$ transmission energy

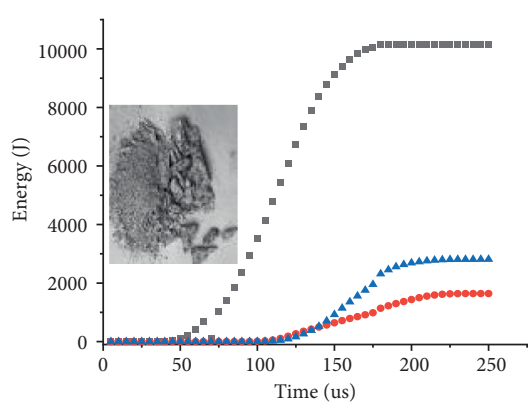

- incident energy

- reflection energy

$\Delta$ transmission energy
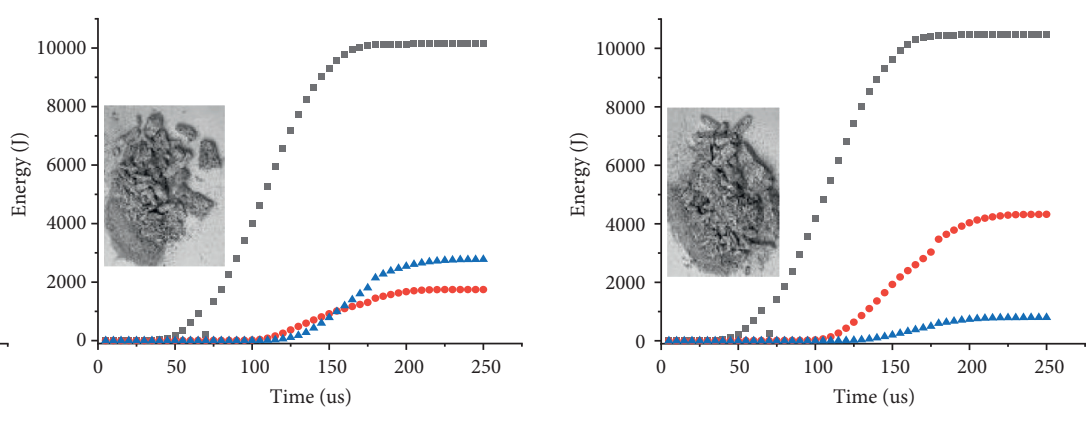

- incident energy

- reflection energy

- incident energy

- reflection energy

- transmission energy

$\mathrm{LDR}=1.0$

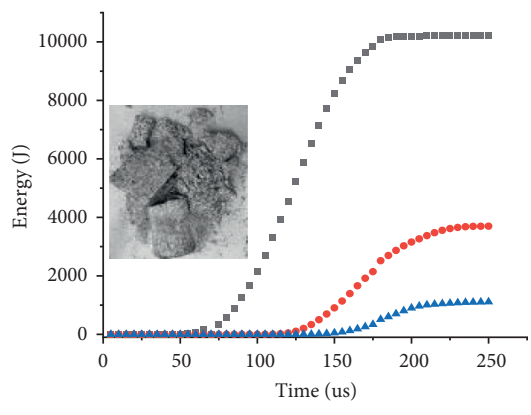

- incident energy

- reflection energy

$\Delta$ transmission energ

$\mathrm{LDR}=2.0$

$\mathrm{LDR}=1.2$

$\mathrm{LDR}=1.5$

FIGURE 4: Different energy time history curves of different length-to-diameter ratios of granite specimens.

fractal dimension. Take the logarithm for (5), the following equation is obtained:

$$
\lg Y=\lg \frac{m(x)}{m_{t}}=(3-D) \lg \left(\frac{x}{x_{m}}\right),
$$

where $(3-D)$ is the fitting line slope in Figure 6. The result of fractal dimension are shown in Table 2 .

As shown in Figure 6, the fitting line shows that the obvious fractal distribution characteristic is in granite fragments. Gao et al. [26] deemed rock macroscopic breakages to consist of many groups of small breakages.
Small breakages are consist of lots of microcracks. There is a self-similarity characteristic in the specimen crack evolution process, and specimen broken fragments also have the same characteristic. So, the fragments' fractal characteristic can be described as a rock broken process. Under impact loading conditions, the rock fragment fractal dimension is in some certain ranges, and the most granite fragment fractal dimension is in the 2-3 range. Fractal dimension is not only related to the experiment condition but also related to rock characteristic. And fractal dimension change is closely related to the change of rock characteristic [27]. 
TABLE 2: The results of sieving test of granite specimens fragments.

\begin{tabular}{|c|c|c|c|c|c|c|c|}
\hline \multirow{2}{*}{ LDR } & \multicolumn{5}{|c|}{ Accumulated mass percentage on each sieving mesh (\%) } & \multirow{2}{*}{ Fractal dimension D } & \multirow{2}{*}{ Fragment average particle size $(\mathrm{mm})$} \\
\hline & $0-2.5 \mathrm{~mm}$ & $2.5 \sim 5 \mathrm{~mm}$ & $5-10 \mathrm{~mm}$ & $10-20 \mathrm{~mm}$ & $20-50 \mathrm{~mm}$ & & \\
\hline 0.5 & 15.791 & 15.789 & 31.578 & 36.842 & 0 & 2.357 & 8.638 \\
\hline 0.6 & 19.172 & 15.349 & 35.321 & 30.158 & 0 & 2.42 & 7.986 \\
\hline 0.7 & 27.76 & 12.214 & 20.023 & 40.003 & 0 & 2.536 & 8.246 \\
\hline 0.8 & 15.386 & 11.538 & 26.923 & 38.461 & 7.692 & 2.336 & 11.052 \\
\hline 0.9 & 13.515 & 8.108 & 16.216 & 43.243 & 18.918 & 2.285 & 14.772 \\
\hline 1 & 23.531 & 11.764 & 17.647 & 29.411 & 17.647 & 2.498 & 12.566 \\
\hline 1.2 & 9.092 & 6.818 & 11.363 & 15.909 & 56.818 & 2.212 & 23.463 \\
\hline 1.5 & 9.679 & 4.838 & 9.677 & 27.419 & 48.387 & 2.194 & 22.061 \\
\hline 2 & 4.126 & 2.061 & 4.123 & 13.402 & 76.288 & 1.94 & 29.135 \\
\hline
\end{tabular}

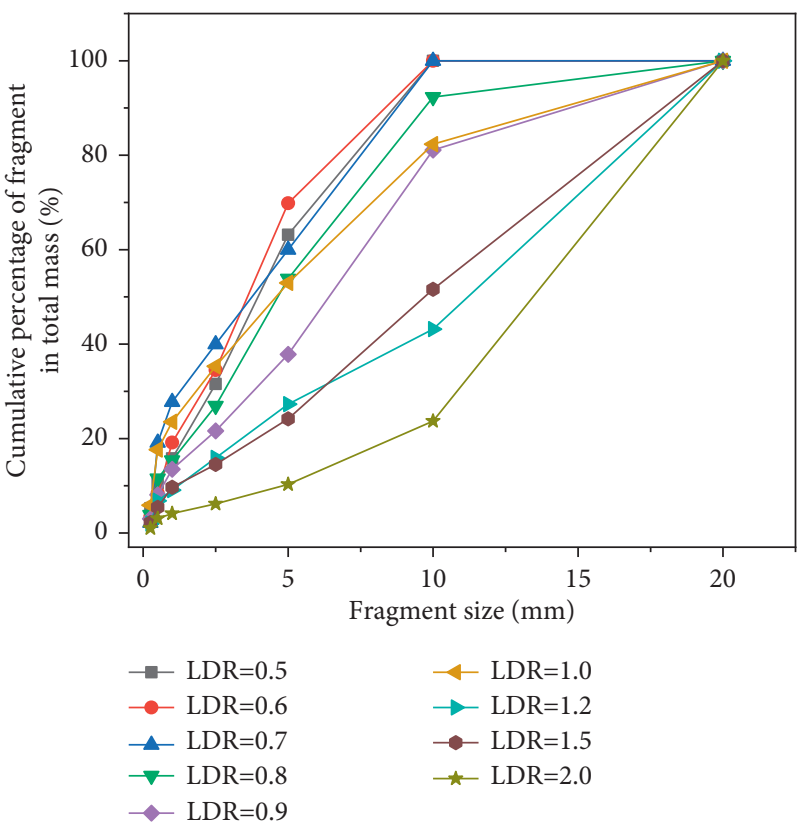

FIGURE 5: Fragment distribution of different length-to-diameter ratios and cumulative mass percentage on the sieving mesh.

As shown in Figure 7, with the increase of specimens' length-to-diameter ratios, specimens' average fragment increases gradually. When specimen length-to-diameter ratios are to grow from 0.5 to 2 , the specimen average fragments are to grow from 8.638 to 29.135 . With the specimen length-todiameter ratios decreasing, the specimen's fragments are more homogeneous. When the length-to-diameter ratios are $0.5,0.6$, and 0.7, the specimens broken fragment sizes are almost the same. It is shown that under the same impact loading condition, within a certain length-to-diameter ratio range, the higher the specimen energy utilization rate, the rock specimen broken fragments are more homogeneous. Outside the range, specimen fragments will become less homogeneous.

4.3. Fractal Dimension and Dynamic Loading Parameters. The specimen evolution process was to happen from microscopic damage to macroscopic fracture. Both the geometric feature and the digital feature of mechanical properties show good self-similarity [25]. After specimen fracture, the specimen broken fragments distribution is self- similar in Figure 4. As Figure 8 shows, the fractal dimension (D) decreases as the specimen length-to-diameter ratio (LDR) increases. Both $D$ and LDR show a certain linear correlation. In the experiment, the length-to-diameter ratio was increased from 0.5 to 2 , and the fractal dimension was decreased from 2.357 to 1.94 .

With the specimens' LDR increasing, the energy dissipation density decreases. When LDR is 0.5 , the specimen energy dissipation density is $5.028 \mathrm{~J} / \mathrm{cm}^{-3}$. When LDR is 2 , the specimen energy dissipation density is $1.563 \mathrm{~J} / \mathrm{cm}^{-3}$. With specimen energy dissipation density increasing, the specimen damage is more thorough. It can explain the result in Figure 4. When the specimen size is small, the specimen is broken more thoroughly than large-sized specimen fragments. It can be seen from the fitting curve that there is a critical LDR value; that is, the relationship between energy dissipation density and LDR is relevant in a certain LDR range.

In the experiment, energy dissipation density can reflect the rock's toughness characteristic, and energy dissipation density means the dissipated energy per unit volume of rock. The energy dissipation density parameter takes many 


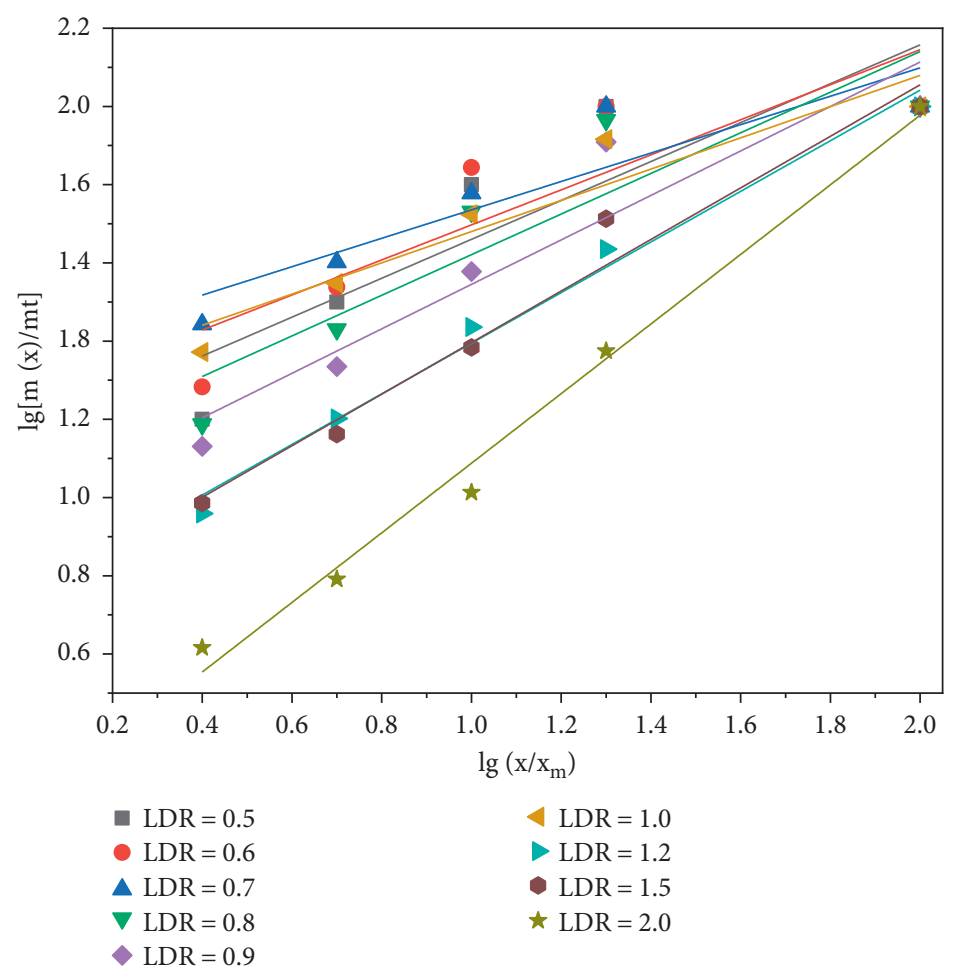

Figure 6: $\lg \left[m(x) / m_{t}\right]-\lg x / x_{m}$ curve of fragmentation distribution of different length-to-diameter ratios.

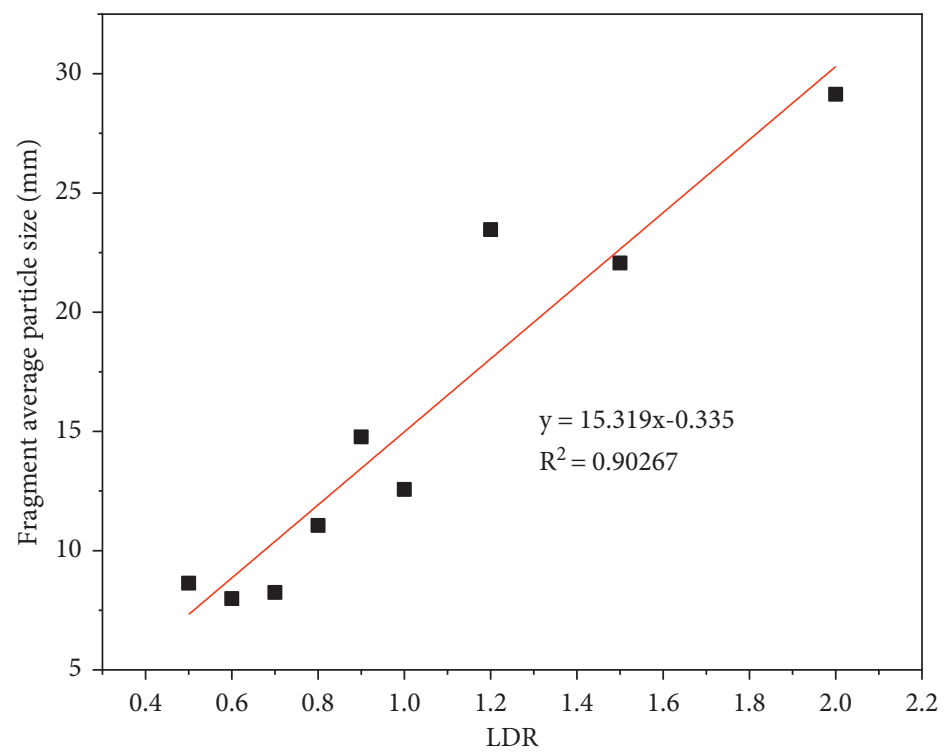

FIGURE 7: Correlation between specimen length-to-diameter ratios and average specimen fragmentation.

influence factors into account in the test, and it is close to the actual toughness value. As shown in Figure 9, with specimen fragment fractal dimension also increases, specimen energy dissipation density increasing. In other words, as the fractal dimension increases, the specimens are broken more thoroughly. Lots of cracks developed and expanded which caused rock damage. The energy dissipation density is increasing gradually, the crack extension velocity is increasing more rapidly, while the fractal dimension is also increasing gradually. Fractal geometry can well describe the regularity of irregular things in nature. Rock fragment fractal characteristics can reflect rock broken mode, and rock fragment fractal dimension shows some physical mechanism in the rock broken evolution process [28-30]. Under a $0.75 \mathrm{MPa}$ impact loading condition, rock will suffer damage and failure. The rock broking process is also called the fractal developed process. Besides, the fragment fractal dimension is an ideal statistical parameter of rock fragments.

With the fractal dimension increasing, the energy dissipation density is also increasing. It is shown that when the 


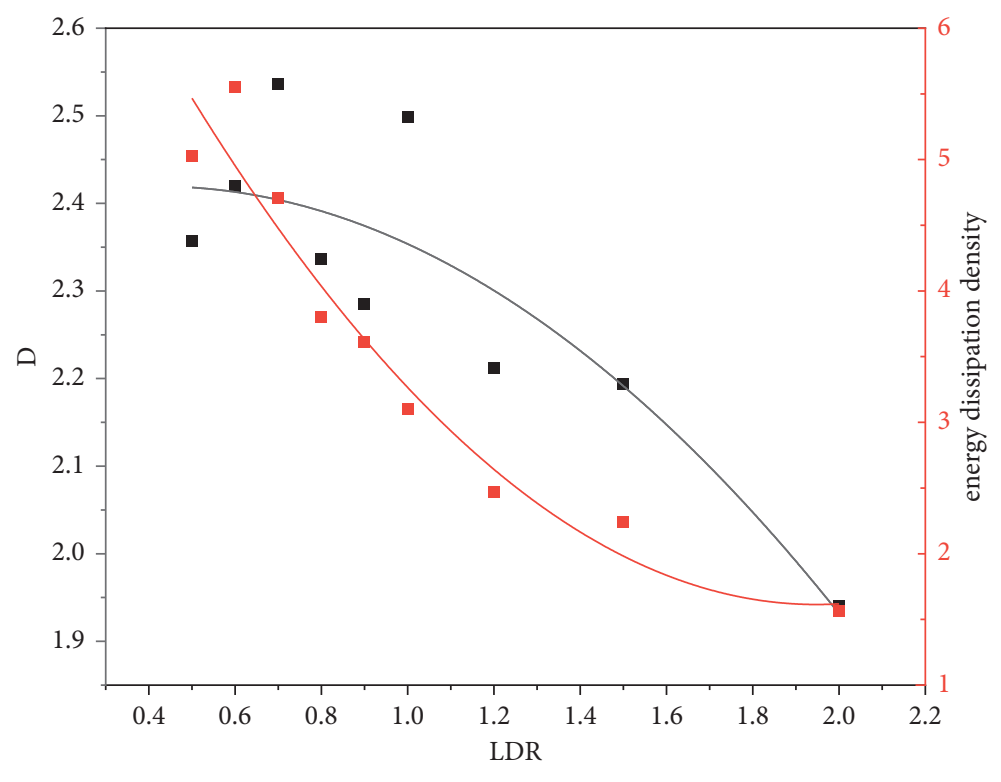

- D

- energy dissipation density

FIGURE 8: Correlation between specimen fractal dimension and specimen length-to-diameter ratios.

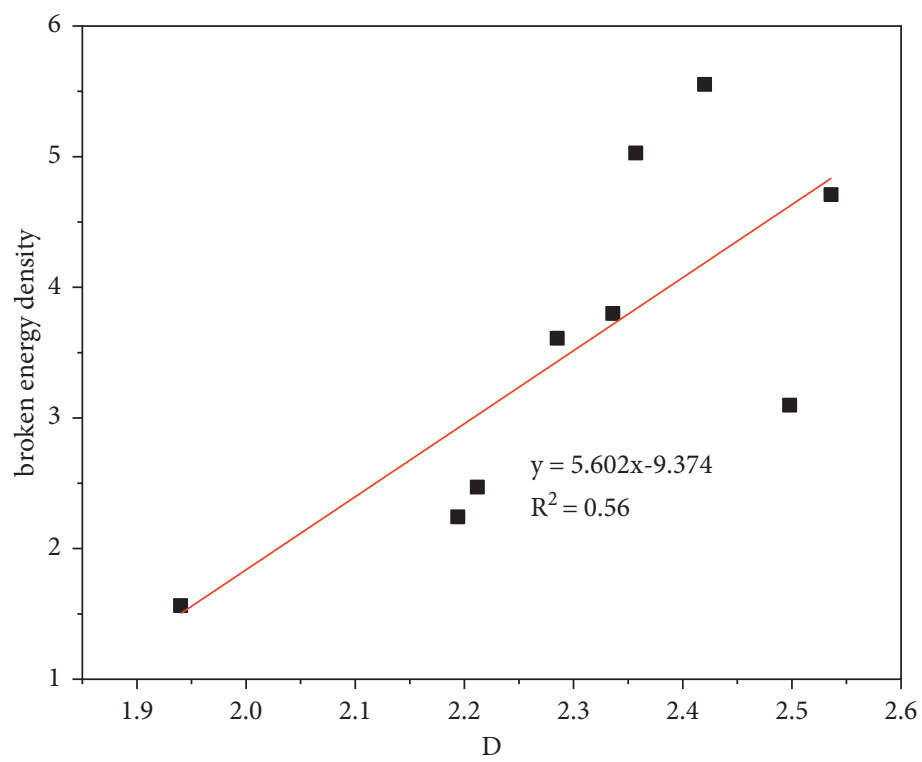

FIgURE 9: Correlation between specimen fractal dimension and specimen broken energy density.

specimens are broken more thoroughly, the energy dissipated is higher. There is a positive correlation between fractal dimension and energy dissipation density.

\section{Conclusions}

This study used SHPB tests and studied dynamic granite fragmentation characteristics of different length-to-diameter ratios. The stress-strain curves and rock fragmentation characteristics were obtained. The sieving mesh is used to screen the rock fragments, and the rock fragmentation distribution curve and the fractal dimension $(D)$ were obtained by the statistical date. Finally, the research analyzed the correlation between rock dynamic parameters and fractal dimension. The central findings are as follows:

(1) The granite energy-time history curve and the stressstrain curve show similar regular before the peak. The difference is that the stress-strain curve shows a downward trend in the postpeak stage, while the energy time history curve remains stable in the postpeak stage.

(2) The specimen fragment degree is negatively correlated with the specimen length-to-diameter ratio. The specimen energy dissipation density and the 
specimen fragment degree increase as the specimens' length-to-diameter ratio increases. If the length-todiameter ratio of specimens is $0.5-0.9$, the time history curve is closer than others. The length-todiameter ratios of rock specimens of 0.5-0.9 are more suitable for SPHB testing.

(3) With the specimen length-to-diameter ratios increasing, the rock specimen fractal dimension decreases. The granite specimens' fractal dimensions are in the range of 1.94-2.536. The result shows that granite fragment distribution similarity is good.

(4) The specimen fractal dimension is positively related to the specimen's energy dissipation density. With the fractal dimension increasing, the specimen energy dissipation density increases. In other words, the more energy per unit volume the specimen absorbs, the more thoroughly the specimen is broken.

\section{Data Availability}

The data used to support the findings of this study have not been made available because the experimental data involved in the paper are all obtained based on the authors' designed experiments and need to be kept confidential; they are still using the data for further research.

\section{Conflicts of Interest}

The authors declare that they have no conflicts of interest.

\section{Acknowledgments}

This work was financially supported by the National Natural Science Foundation of China (nos. 51974009 and 52004005), the China Postdoctoral Science Foundation (2021M691185), the Key Research and Development Projects in Anhui Province (Grant no. 201904A07020010), the Anhui Provincial Natural Science Foundation (no. 2008085QE222), the Postdoctoral Science Foundation of Anhui Province (no. 2021B513), and the Independent Research Fund of the State Key Laboratory of Mining Response and Disaster Prevention and Control in Deep Coal Mines (Anhui University of Science and Technology) (no. SKLMRDPC19ZZ012).

\section{References}

[1] F. Feng, S. Chen, Y. Wang, W. Huang, and Z. Han, "Cracking mechanism and strength criteria evaluation of granite affected by intermediate principal stresses subjected to unloading stress state," International Journal of Rock Mechanics and Mining Sciences, vol. 143, Article ID 104783, 2021.

[2] S.-J. Chen, F. Feng, Y.-J. Wang et al., "Tunnel failure in hard rock with multiple weak planes due to excavation unloading of in-situ stress," Journal of Central South University, vol. 27, no. 10, pp. 2864-2882, 2020.

[3] F. Feng, X. Li, J. Rostami, D. Peng, D. Li, and K. Du, "Numerical investigation of hard rock strength and fracturing under polyaxial compression based on Mogi-Coulomb failure criterion," International Journal of Geomechanics, vol. 19, no. 4, Article ID 04019005, 2019.
[4] C. Tanusree, M. Sunita, L. Josh, H. Brent, and B. Brady, "Characterization of three Himalayan rocks using a split Hopkinson pressure bar," International Journal of Rock Mechanics and Mining Sciences, vol. 85, pp. 112-118, 2016.

[5] L. Jin, W. Yu, and X. Du, "Dynamic size effect of concrete under tension: a numerical study[J]," International Journal of Impact Engineering, vol. 132, no. OCT, pp. 103318.1103318.13, 2019.

[6] P. Chen, L. Changyong, and W. Yang, "Size effect on peak axial strain and stress-strain behavior of concrete subjected to axial compression," Construction and Building Materials, vol. 188, pp. 645-655, 2018.

[7] X. F. Li, H. B. Li, Q. B. Zhang, J. L. Jiang, and J. Zhao, "Dynamic fragmentation of rock material: characteristic size, fragment distribution and pulverization law," Engineering Fracture Mechanics, vol. 199, pp. 739-759, 2018.

[8] Y. Luo, G. Wang, X. Li et al., "Analysis of energy dissipation and crack evolution law of sandstone under impact load," International Journal of Rock Mechanics and Mining Sciences, vol. 132, Article ID 104359, 2020.

[9] H. Wu, B. Dai, and L. Cheng, "Experimental study of dynamic mechanical Response and energy dissipation of rock having a circular opening under impact loading," Mining, Metallurgy \& Exploration, vol. 38, pp. 1-14, 2021.

[10] L. Weng, Z. Wu, and Q. Liu, "Energy dissipation and dynamic fragment of dry and water-saturated siltstones under sub-zero temperatures," Engineering Fracture Mechanics, vol. 220, Article ID 106659, 2019.

[11] C.-y. Liu, G.-m. Zhao, W.-s. Xu et al., "Experimental investigation on failure process and spatio-temporal evolution of rockburst in granite with a prefabricated circular hole," Journal of Central South University, vol. 27, no. 10, pp. 2930-2944, 2020.

[12] Z. X. Zhang, S. Q. Kou, L. G. Jiang, and P.-A. Lindqvist, "Effects of loading rate on rock fracture: fracture characteristics and energy partitioning," International Journal of Rock Mechanics and Mining Sciences, vol. 37, no. 5, pp. 745-762, 2000.

[13] D. E. Grady, "Length scales and size distributions in dynamic fragmentation," International Journal of Fracture, vol. 163, no. 1-2, pp. 85-99, 2010.

[14] B. Lundberg, "A split Hopkinson bar study of energy absorption in dynamic rock fragmentation," International Journal of Rock Mechanics and Mining Sciences \& Geomechanics Abstracts, vol. 13, no. 6, pp. 187-197, 1976.

[15] L. Hong, Z.-L. Zhou, T.-B. Yin, G.-Y. Liao, and Z.-Y. Ye, "Energy consumption in rock fragmentation at intermediate strain rate," Journal of Central South University of Technology, vol. 16, no. 4, pp. 677-682, 2009.

[16] B. B. Mandelbrot, The Fractal Geometry of nature, W. H. Freeman, San Francisco, CA, USA, 1983.

[17] S. W Tyler, "Application of fractal mathematics to soil-water retention estimation," Soil Science Society of America Journal, vol. 53, no. 4, pp. 987-996, 1989.

[18] S. W. Tyler and S. W. Wheatcraft, "Fractal scaling of soil particle-size distributions: analysis and limitations," Soil Science Society of America Journal, vol. 56, no. 2, pp. 362-369, 1992.

[19] M. N. Bagde, A. K. Raina, and A. K. Chakraborty, "J.L. Jethwa Rock mass characterization by fractal dimension," Engineering Geology, vol. 63, no. 1-2, pp. 141-155, 2002.

[20] X. P. Zhou and N. Xiao, "Analysis of fracture properties of three-dimensional reconstructed rock model using hierarchical-fractal annealing algorithm," Engineering Geology, vol. 256, 2019. 
[21] Y. Cai, S. Yu, and Y. Lu, "Experimental study on granite and the determination of its true strain-rate effect," Latin American Journal of Solids and Structures, vol. 12, no. 4, pp. 675-694, 2015.

[22] E. D. H. Davies and S. C. Hunter, "The dynamic compression testing of solids by the method of the split Hopkinson pressure bar," Journal of the Mechanics and Physics of Solids, vol. 11, no. 3, pp. 155-179, 1963.

[23] X. F. Li, Q. B. Zhang, H. B. Li, and J. Zhao, "Grain-based discrete element method (GB-DEM) modelling of multi-scale fracturing in rocks under dynamic loading," Rock Mechanics and Rock Engineering, vol. 51, no. 12, pp. 3785-3817, 2018.

[24] W. Wang, H. Li, and Q. Qi, "Study on fissure development rule of overlying strata influenced by mining based on fractal theory," Journal of China Coal Society, vol. 39, no. 6, pp. 1023-1030, 2014

[25] H. Xie, F. Gao, and H. Zhou, "Fractal fracture and fragment in rocks," Journal of Disaster Prevention and Mitigation Engineering, vol. 23, no. 4, pp. 1-9, 2003.

[26] F. Gao, X. He-Ping, and P. Zhao, "Fractal properties of sizefrequency distribution of rock fragments and the influence of meso-structure," Chinese Journal of Rock Mechanics and Engineering, vol. 13, no. 3, pp. 240-246, 1994.

[27] Y.-F. Xu and Q.-H. Zhang, "Influence of confining pressure on fractal dimension of sandstone fragment distribution," Chinese Journal of Rock Mechanics and Engineering, vol. 15, no. 3, pp. 250-254, 1996.

[28] X.-B. Tu, S.-J. Wang, and Z.-Q. Yue, "Fractal fragment of weathered rock and its application to engineering geology," Chinese Journal of Rock Mechanics and Engineering, vol. 24, no. 4, pp. 587-595, 2005.

[29] M. Yu, J. Zuo, Y. Sun, C. Mi, and Z. Li, "Investigation on fracture models and ground pressure distribution of thick hard rock strata including weak interlayer," International Journal of Mining Science and Technology, 2021.

[30] J. Zuo, M. Yu, and C. Li, "Analysis of surface cracking and fracture behavior of a single thick main roof based on similar model experiments in western coal mine, China," Natural Resources Research, vol. 30, no. 2, pp. 1-24, 2020. 